Universidade de Brasília

Faculdade de Economia, Administração, Contabilidade e Ciências da Informação e Documentação

NATALIA FERNANDES CAMARGO

\title{
ANÁLISE DO COMPROMETIMENTO ORGANIZACIONAL NA ADMINISTRAÇÃO CENTRAL DOS CORREIOS
}

\author{
Brasília - DF \\ Dezembro / 2009
}




\title{
ANÁLISE DO COMPROMETIMENTO ORGANIZACIONAL NA ADMINISTRAÇÃO CENTRAL DOS CORREIOS
}

Trabalho de Conclusão de Curso apresentado ao Departamento de Administração como requisito parcial à obtenção do título de Bacharel em Administração.

Professor Orientador: Doutor, Tomás de Aquino Guimarães

\author{
Brasília - DF \\ Dezembro / 2009
}


Camargo, Natalia Fernandes.

Análise do Comprometimento Organizacional na Administração Central dos Correios / Natalia Fernandes Camargo. - Brasília, 2009. $47 \mathrm{f}$ : : il.

Monografia (bacharelado) - Universidade de Brasília, Departamento de Administração, 2009.

Orientador: Prof. Dr. Tomás de Aquino Guimarães, Departamento de Administração.

1. Comprometimento. 2. Comportamento. 3. Organização. I. Título. 


\title{
ANÁLISE DO COMPROMETIMENTO ORGANIZACIONAL NA ADMINISTRAÇÃO CENTRAL DOS CORREIOS
}

\begin{abstract}
A Comissão Examinadora, abaixo identificada, aprova o Trabalho de Conclusão do Curso de Administração da Universidade de Brasília da aluna
\end{abstract}

\section{Natalia Fernandes Camargo}

\author{
Doutor, Tomás de Aquino Guimarães \\ Professor-Orientador \\ Doutor, Pedro Paulo Murce Meneses \\ Professor-Examinador
}

Brasília, 10 de dezembro de 2009 
Dedico este trabalho aos meus pais, Ivone Fernandes Camargo e Marcelo de Almeida Camargo, que, com o amor incondicional, me levaram a acreditar em mim mesma e a desafiar obstáculos. 
"O segredo do sucesso não é prever o futuro. É preparar-se para um futuro que não pode ser previsto." (Michael Hammer) 
RESUMO

As empresas do século XXI atuam em ambientes competitivos e necessitam adotar ações proativas visando aumentar os respectivos níveis de competitividade. Nessa linha, a adoção de políticas de gestão de pessoas que impulsionem o desempenho dos empregados e aumentem o nível de comprometimento com a organização, fazem parte do contexto de suporte à competitividade. A análise do nível de comprometimento de funcionários, portanto, representa etapa fundamental para as práticas de gestão de pessoas. Nesse cenário, o objetivo do presente trabalho é analisar o enfoque de comprometimento organizacional percebido por funcionários da Administração Central dos Correios e as relações existentes entre o grau de comprometimento e dados demográficos dos colaboradores. Desta forma foi realizada uma pesquisa de caráter descritivo, do tipo quantitativa, que por meio de um questionário desenvolvido por Meyer e Allen (1991) possibilitou atingir os objetivos da pesquisa. O referencial teórico explorou os principais conceitos e tipologias relacionados com o tema pesquisado, sendo que comprometimento organizacional é definido, para os efeitos deste trabalho, como um vínculo de natureza afetiva, normativa ou calculativa estabelecido entre o indivíduo e a organização. Os dados foram coletados junto a funcionários da Administração Central dos Correios, em Brasília - DF. O questionário utilizado englobou os três enfoques de comprometimento estudado, a partir de uma escala do tipo Likert de concordância ( $1=$ discordo totalmente até $5=$ concordo totalmente); bem como questões sócio-demográficas. Esse questionário foi distribuído pessoalmente e por intermédio da Intranet da empresa. A amostra atendeu a proporção mínima indicada por Richardson, 310 funcionários, e caracteriza-se como amostra por acessibilidade. Os dados foram analisados com o auxílio do software SPSS versão 13, mediante técnicas estatísticas descritivas (média, moda, desvio padrão) e inferenciais (Teste$\mathrm{T}$ ). Os resultados revelaram o comprometimento afetivo como o predominante na empresa. A pesquisa, também, identificou uma significativa diferença da percepção do comprometimento nos quesitos sexo, idade, tempo de serviço e função ocupada. A pesquisa realizada pode contribuir para outros estudos sobre comprometimento organizacional, principalmente no que se refere à relação entre as políticas de gestão de pessoas e o comprometimento.
1. Comprometimento
2. Comportamento
3. Organização 


\section{LISTA DE ILUSTRAÇÕES}

Figura 1 - Antecedentos, Correlatos e Consequentes do Comprometimento. .........22 


\section{LISTA DE TABELAS}

Tabela 1 - Dados Demográficos:

Tabela 2 - Dados do Comprometimento Calculativo: ............................................. 32

Tabela 3 - Dados do Comprometimento Afetivo:......................................................33

Tabela 4 - Dados do Comprometimento Normativo: ...............................................33

Tabela 5 - Análise Descritiva dos Enfoques do Comprometimento Organizacional: 34 Tabela 6 - Teste T entre Médias do Comprometimento x Variáveis Demográficas: 36

Tabela 7 - Teste T de Significância entre o Comprometimento x Variáveis

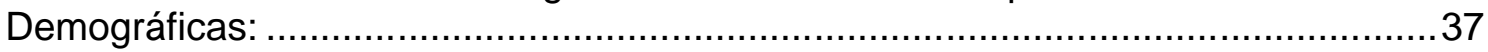




\section{LISTA DE ABREVIATURAS E SIGLAS}

ECT - Empresa Brasileira de Correios e Telégrafos 


\section{SUMÁRIO}

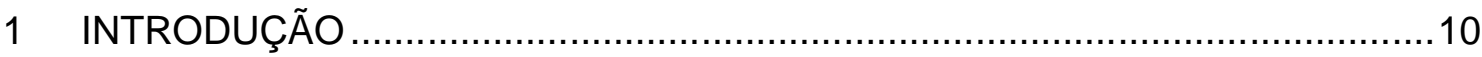

1.1 Contextualização do Assunto ……………………..............................10

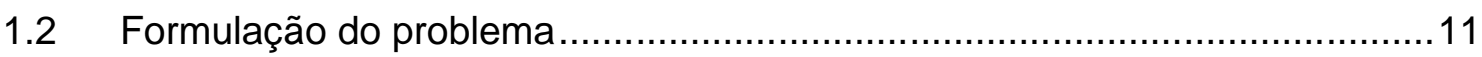

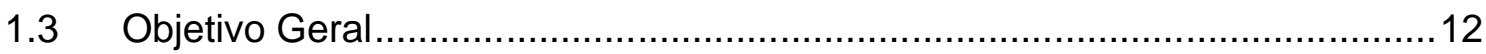

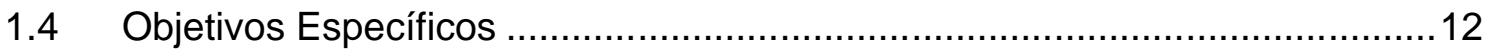

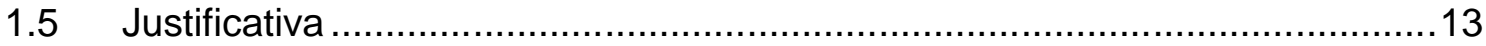

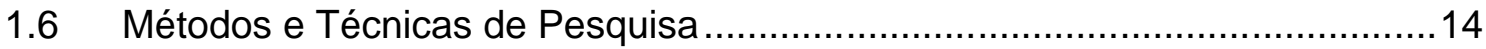

1.7 Estrutura e Organização da Monografia ..................................................14

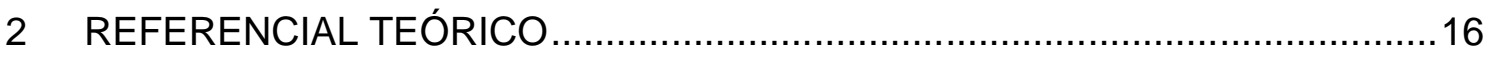

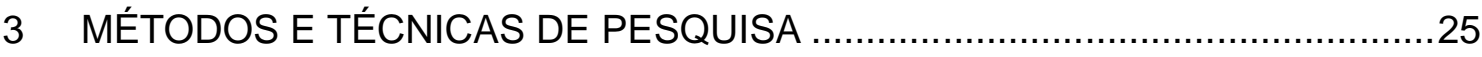

3.1 Tipo e descrição geral da pesquisa ........................................................25

3.2 Caracterização da organização, setor ou área ...........................................25

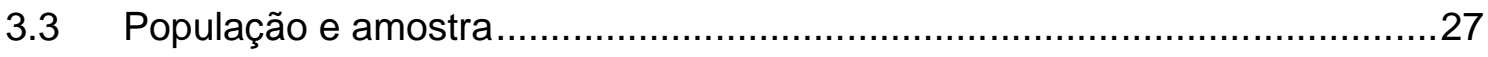

3.4 Caracterização dos instrumentos de pesquisa ...........................................28

3.5 Procedimentos de coleta e de análise de dados .........................................29

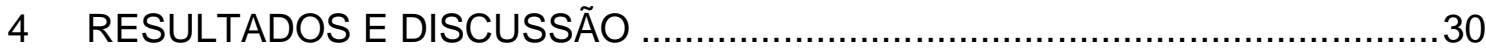

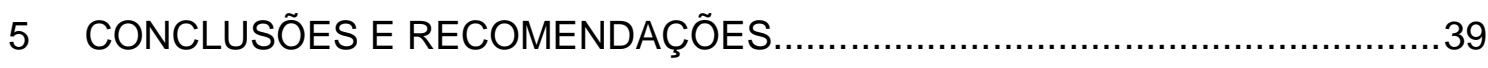

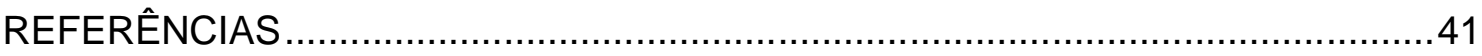

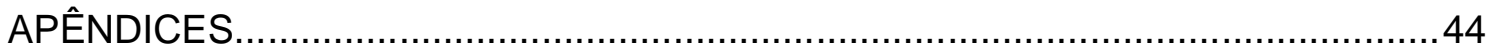

Apêndice A - Organograma da Administração Central dos Correio .........................44

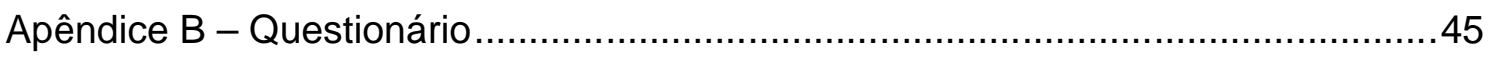




\section{INTRODUÇÃO}

Neste início de século XXI as organizações estão imersas em um ambiente dinâmico, com constantes mudanças tecnológicas, sociais, econômicas e políticas. Nesse contexto, a sobrevivência das empresas está fundamentada na busca pela competitividade, que vem se tornando cada vez mais acirrada.

Com a agilidade das mudanças e competitividade do mercado, uma empresa prevenida, que possui visão de futuro e informação, acompanha a evolução da tecnologia e as mudanças de mercado. Portanto, é recomendável que a empresa esteja atenta a este ambiente com rápidas e profundas transformações e busque novas idéias, antecipando-se e sendo agente da própria mudança.

Este cenário da busca pela competitividade não está centrado apenas em estratégias adequadas de mercado, finanças, logística e marketing. A vantagem competitiva também está nos colaboradores da empresa, que internalizam os objetivos estratégicos da organização e o executam como se fossem seus próprios objetivos.

Nesse sentido, pode-se dizer que quando um indivíduo se identifica com a organização e deseja manter-se como um membro dela para satisfazer seus interesses e facilitar o alcance da missão organizacional, há a identificação do comprometimento organizacional (FLAUZINO; BORGES-ANDRADE, 2008).

Nessa linha, cabe aos administradores de sucesso lidar com essas incertezas. No entanto, é necessário que haja comprometimento por parte dos funcionários. Assim, "os funcionários comprometidos com sua empresa tornam-se sua margem competitiva" (DESSLER, 1996, p. 5). Desta forma, os estudos relacionados ao comprometimento organizacional são favoráveis à busca de estratégias para aumentar o comprometimento organizacional do empregado, pois consideram esta ação uma vantagem competitiva sobre as outras empresas que não tem seguido tal estratégia (SILVA, 2007).

É evidente que um alto grau de comprometimento com a organização contribui para que as empresas alcancem seus objetivos, como relata Muller (2005). Assim, o 
sucesso da organização está nos colaboradores comprometidos e dispostos a lutar pelos objetivos da organização.

\subsection{Contextualização do Assunto}

A consecução de objetivos, o alcance de metas e a competitividade de uma empresa dependem, necessariamente, do comprometimento organizacional de seus membros trabalhadores. Por isso faz-se necessário a realização de pesquisas e estudos nesse campo.

A pesquisa sobre comprometimento organizacional ganhou impulso no final da década de 1970, fortemente marcado pela investigação do comprometimento no trabalho. No entanto foi a partir de 1990 que a visão do comprometimento foi reconhecida como um fenômeno multidimensional devido à sua 'constelação de conceitos' (BASTOS, 1994).

No Brasil, as pesquisas de Chang (2001), Medeiros (2003), Bastos (1994) e Bandeira (1999) são provas do crescente interesse pelo tema. Esses pesquisadores estão contribuindo para um conceito nacional do comprometimento, bem como para o desenvolvimento de instrumentos de mensuração mais completos (SILVA, 2007).

Os estudos acerca do comprometimento têm introduzido a análise do tema sob diversos aspectos, a serem tratados ao longo do próximo capítulo deste trabalho e que serão a base para a análise do comprometimento organizacional identificado nos Correios.

\subsection{Formulação do problema}

Os Correios, uma organização pública que trabalha com a pontualidade de seus serviços e que é reconhecida pelos brasileiros como uma das cinco empresas mais confiáveis, devem estar atentos ao grau de comprometimento de seus funcionários, pois a falta de comprometimento pode afetar a imagem do serviço prestado pela empresa. 
Segundo Randall (1998) citado por Silva (2007), os estudos acerca do comprometimento organizacional têm revelado que baixos níveis de comprometimento remetem à baixa qualidade de trabalho, possíveis pedidos de demissão, lentidão no avanço da carreira, atrasos, maior rotatividade e absenteísmo.

A importância deste estudo está na possibilidade de um maior entendimento acerca das relações existentes entre determinadas variáveis e comportamentos que devam contribuir para o alcance das metas e objetivos organizacionais, gerando assim, o estabelecimento de relacionamentos desejáveis no ambiente de trabalho, propícios a obtenção do sucesso contínuo.

Considerando esse contexto, esta pesquisa propõe-se a responder a seguinte questão: qual o enfoque de comprometimento organizacional predominante entre funcionários da Administração Central dos Correios e possíveis relações entre variáveis demográficas e funcionais desses funcionários com a percepção do comprometimento?

\subsection{Objetivo Geral}

Identificar o enfoque de comprometimento organizacional predominante nos funcionários da Administração Central dos Correios e possíveis relações entre variáveis demográficas e funcionais desses funcionários com a percepção a respeito do comprometimento.

\subsection{Objetivos Específicos}

- Identificar o enfoque geral de comprometimento organizacional predominante nos funcionários da Administração Central dos Correios.

- Identificar as principais características pessoais inerentes aos funcionários entrevistados em cada um dos focos de comprometimento. 


\subsection{Justificativa}

O sucesso dos objetivos estratégicos da empresa advém do comprometimento de seus funcionários. Assim, ter empregados comprometidos é benéfico para o aumento do desempenho da organização.

O comprometimento é um importante conceito para as organizações e muitas empresas têm reconhecido que a qualidade dos serviços tem como base o comprometimento de seus funcionários. Segundo Muller (2005, p. 511), "o comprometimento está baseado na evidência de que dele derivam atitudes e comportamentos que aumentam o desempenho do colaborador".

O comprometimento organizacional é um tema que deve ser bem entendido pela organização para uma melhor gestão das pessoas e conseqüente sucesso nos negócios.

A análise do comprometimento organizacional por meio do estudo de suas dimensões possui uma grande aplicabilidade prática visto que oferece embasamento teórico aos gestores, auxiliando-os no direcionamento de esforços com o objetivo de engajar o colaborador à empresa.

Assim, esta pesquisa busca verificar no contexto da Administração Central dos Correios, percepções sobre o comprometimento organizacional dos funcionários da empresa, a fim de impulsionar novas políticas de gestão de pessoas que possam elevar o grau de comprometimento de seus funcionários.

Este trabalho vem a contribuir propiciando uma base de auxílio à tomada de decisões no sentido de implantar ações e políticas para desenvolver as bases de comprometimento organizacional dos Correios de forma a facilitar a consecução dos objetivos organizacionais. 


\subsection{Métodos e Técnicas de Pesquisa}

A pesquisa do comprometimento organizacional realizada na Administração Central dos Correios se configura como de natureza quantitativa, uma vez que avalia a forma de comprometimento percebida por um conjunto de colaboradores da empresa, mediante levantamento de percepções.

A coleta de dados se deu por meio de um questionário, já validado, que busca identificar em qual nível de comprometimento o funcionário está enquadrado. Este modelo foi desenvolvido por Meyer e Allen (1991) e adaptado ao Brasil por Siqueira (2001), além de incluir itens referentes a dados demográficos e funcionais dos respondentes. O questionário foi aplicado a 310 funcionários da Administração Central, cuja amostra foi do tipo probabilística, por acessibilidade.

A análise de dados se deu por meio do software estatística SPSS, por meio de estatística descritiva e Teste $\mathrm{T}$, de modo a permitir análises do comprometimento predominantes e tendências de comprometimento em função de características dos pesquisados.

\subsection{Estrutura e Organização da Monografia}

O presente trabalho está estruturado em quatro capítulos que orientarão o trabalho sobre comprometimento organizacional a ser desenvolvido nos Correios. Para tanto, o primeiro capítulo apresentou o problema de pesquisa: caracterização geral do tema, objetivos e justificativa da pesquisa a ser desenvolvida.

O segundo capitulo versa sobre o referencial teórico acerca do comprometimento. Esse capítulo tratará das diversas vertentes teóricas, dos conceitos identificados nesse tema e dos principais enfoques e correlatos envolvidos no assunto.

O capítulo 3 expõe a metodologia a ser aplicada na pesquisa sobre a forma de comprometimento predominante na Administração Central dos Correios, bem como a forma em que os dados serão coletados e analisados. Esse capítulo também 
envolve a caracterização da organização a ser pesquisada e possui de um cronograma que estabelece as datas previstas das ações necessárias para a conclusão da elaboração deste trabalho.

Nos elementos pós-textuais tem-se a lista de referências literárias que deram subsídios para o desenvolvimento do projeto e o modelo do questionário a ser aplicado na coleta de dados. 


\section{REFERENCIAL TEÓRICO}

O presente capítulo aborda uma revisão bibliográfica do tema estudado, servindo como referencial teórico para a pesquisa a ser desenvolvida.

Na literatura, há contribuição de distintas disciplinas científicas, durante mais de três décadas de estudo, sobre as diversas concepções do comprometimento organizacional (ZANELLI, BORGES-ANDRADE, BASTOS \& COLS, 2004).

A Sociologia, as Teorias Organizacionais e a Psicologia Social foram três áreas de teoria contribuíram para a investigação do comprometimento organizacional. A partir dessas origens de contribuição, foi possível identificar cinco grandes vertentes de pesquisa: o enfoque afetivo; instrumental; sociológico; comportamental e normativo (BASTOS, 1993).

O comprometimento pode ser dirigido a diversos focos. De acordo com Naves e Coleta (2003), múltiplos aspectos podem ser alvos do comprometimento do indivíduo: a organização, o sindicato, a carreira, o grupo de colegas, o conjunto de tarefas executadas, os objetivos e os valores.

Este trabalho se limitará à abordagem do comprometimento com foco na organização, no qual ainda "podem ser identificadas distintas abordagens que implicam em conceituação e propostas de mensuração diferenciadas" (BASTOS, 1994 , p. 41), ou seja, o comprometimento com foco na organização ou comprometimento organizacional possui múltiplas bases de naturezas distintas.

A seguir, serão tratados com mais aprofundamento os conceitos, as principais vertentes, os antecedentes e os conseqüentes sobre os estilos de comprometimento com foco na organização.

\subsection{Conceito de Comprometimento}

Vários pesquisadores assumem que o comprometimento organizacional é um vínculo existente entre o indivíduo e a organização em que trabalha. No entanto, 
uma divergência do conceito se refere à forma com que esse vínculo é estabelecido. Bandeira, Marques e Veiga (2000) entendem o comprometimento organizacional como um forte vínculo indivíduo-organização, que dispensaria energia e lealdade nesta relação. Este último fator também interpretado por Bastos (1994).

Para Mowday (1982), o vínculo existente nesta relação está caracterizado pelos fatores: esforço, crença e aceitação de valores e objetivos propostos pela organização, bem como o desejo de se manter neste contexto.

Rego e Souto (2002) afirmam que do vínculo derivam atitudes e comportamentos relevantes para a organização, visto que atitudes ligadas à assiduidade, desempenho, pontualidade, intenção de abandono da organização e comportamento são precursores do comprometimento.

Segundo Bastos (1997, p. 101), o vínculo pode ser descrito como "o desejo de permanecer, de continuar; o sentimento de orgulho por pertencer; a identificação, o apego, o envolvimento com objetivos e valores e engajamento, exercer esforço, empenho em favor de".

Enfim, há vários anos o comprometimento organizacional pode ser entendido como um vínculo, ligação, conexão e envolvimento entre o indivíduo e a organização, conforme sugerem distintos autores (Quadro 1).

Kanter (1968) - ligação afetiva e emocional de um indivíduo com o grupo.

Sheldon (1971) - conexão entre a identidade da pessoa e da organização.

Hall at al (1970) - congruência entre as metas individuais e organizacionais.

Buchanan (1974) - ligação afetiva com as metas e valores organizacionais.

Mowday at al. (1982) - identificação e envolvimento do indivíduo com uma organização.

Quadro 1: Definições do Comprometimento Organizacional Fonte: Adaptada da Figura 2 Definições do Comprometimento Organizacional de Silva (2007, p. 23)

Diante do exposto, pode-se afirmar que o comprometimento organizacional é caracterizado por um envolvimento que incita o indivíduo a realizar um esforço em prol da empresa, sendo este afetado pela natureza do vínculo: afetivo, calculativo ou normativo (NAVES e COLETA, 2003). 


\subsection{Comprometimento Afetivo}

O comprometimento afetivo é o enfoque mais abordado no comprometimento organizacional e tem como base as teorias de Etzioni (1975), que foram aprimoradas com os trabalhos de Mowday, Porter e Steers (1979).

O comprometimento afetivo, também designado como atitudinal por alguns autores, é caracterizado pela identificação do funcionário com a organização, desejando manter-se como membro desta, de modo a viabilizar a execução dos objetivos organizacionais (MULLER et al., 2005).

Neste mesmo enfoque, autores como Porter et al. (1979), Mowday (1998) e Meyer e Allen (1997), citados por Silva (2007, p. 30), convergem na idéia de que o comprometimento afetivo possui relação com três componentes "uma forte crença e aceitação das metas e valores da organização; uma disposição em exercer um considerável esforço em nome da organização e um firme desejo de manter-se como membro da organização".

Esses autores complementam essa definição com o sentimento de lealdade que o indivíduo possui com a organização. Corroborando com as idéias de Mowday, Porter e Steers (1982), Bastos (1993, p. 54) afirma que a abordagem atitudinal envolve sentimentos de lealdade, desejo de permanecer na organização e de se esforçar em prol dela, complementando que:

"Quando o comprometimento é assim definido, ele representa algo além da simples lealdade passiva a uma organização. Ele envolve uma relação ativa, na qual o indivíduo deseja dar algo de si próprio para contribuir com o bem-estar da organização."

Assim, este enfoque baseia-se no vínculo emocional e afetivo entre o indivíduo e a organização, na qual o funcionário possui o desejo de contribuir com a organização e demonstra sentimento de orgulho em permanecer nela.

Ao contrário de alguns autores nacionais, os precursores desta corrente assinalam que além das crenças e opiniões dos indivíduos, o comprometimento afetivo pode 
ser interferido pelas ações, bem como o comprometimento com a organização não exclui a probabilidade de comprometimento com outros aspectos do ambiente, como família, sindicato e partido político (BASTOS, 1993).

\subsection{Comprometimento Calculativo}

O enfoque instrumental do comprometimento organizacional tem como base as teorias de Becker (1960) e, posteriormente, Ritzer e Trice (1969) e Hrebiniak e Alluto (1972). Becker (1960, citado por Medeiros e Enders, 1998) afirma que a permanência do indivíduo na organização ocorre devido a custos e benefícios associados a sua saída. Desta maneira, acredita-se que o trabalhador preferia permanecer na empresa, enquanto acreditava receber benefícios dela. Caso contrário, o trabalhador optava por abandonar a organização.

Esta forma de comprometimento também é conhecida como instrumental, continuação ou side bet, que pode ser traduzido como trocas laterais, que seria uma analogia ao tempo, esforço e dinheiro investidos pelos trabalhadores.

Segundo Bastos (1993), o enfoque instrumental teria uma natureza mais sociológica e seria a tendência de se engajar em linhas consistentes de atitudes devido aos custos associados a agir de forma diferente, mecanismo este que envolve investimentos que limitam o raio de ação posterior.

\subsection{Comprometimento Normativo}

A vertente normativa do comprometimento organizacional surgiu com a teoria de Wiener (1982) e posteriores trabalhos de McGee e Ford (1987), ambos influenciados por Etzioni (1975). Para esses autores, os indivíduos comprometidos exibem comportamentos organizacionais que acreditam que seria certo e moral fazê-lo.

O comprometimento normativo pode ser definido como "a totalidade das pressões normativas internalizadas e a conseqüente ação, de maneira a satisfazer os interesses organizacionais" (Wiener, 1982, citado por Silva, 2007, p. 31). 
Wiener e Vardi (1990, citados por Naves e Coleta, 2003) defendem a influência da cultura organizacional nos trabalhadores, a fim de envolvê-los nos ideais da empresa. Os autores ressaltam que a cultura só será influenciável desde que os valores e normas sejam reconhecidos pelos membros como conduta moral e ética.

Outra abordagem desses autores se refere às pressões internalizadas em padrões de comportamento, tais como o sacrifício, a persistência e a preocupação pessoal. Nesse sentido, Bastos (1993, p.58) relata que a cultura é definida como o conjunto de valores que produzem pressões normativas sobre os membros, as quais se associam ao sistema de recompensas para influenciar o comportamento, ou seja, as pressões predispõem o indivíduo a se comportar conforme padrões internalizados:

"Quanto mais forte o comprometimento, maior a predisposição do indivíduo guiar as suas ações por padrões internalizados, mais do que considerações racionais acerca das conseqüências dessas ações. Assim, indivíduos comprometidos apresentam certos comportamento não porque eles calculam que, em os apresentando, obterão benefícios pessoais, mas porque eles acreditam que é certo e moral fazê-lo."

Bandeira, Marques e Veiga (2000) afirmam que esses pesquisadores também acreditam que o comportamento é determinado pelo fator atitudinal, no sentido da atitude como resultado da avaliação dos resultados da ação e pelo fator normativo, acerca da percepção da ação como resultado de pressões normativas, geralmente da cultura da empresa.

Segundo Rego e Souto (2004), o comprometimento normativo é identificado quando o trabalhador interioriza as normas organizacionais ou quando recebe benefícios e experiências que o induzem a sentir vontade de agir reciprocamente.

\subsection{Antecedentes e Conseqüentes do Comprometimento}

Apesar de Bandeira, Marques e Veiga (2000) afirmarem serem recentes os estudos acerca das correlações das políticas organizacionais com o comprometimento considerando, portanto, pouco consistentes em sua totalidade, os estudos nesse sentido perduram desde 1982. 
Estudiosos como Mowday, Portes e Steers (1982) já se preocupavam com a identificação de antecedentes do comprometimento e consolidaram uma estratégia de pesquisa que se define pelo uso de dados quantitativos e emprego de análises estatísticas para identificar vínculos causais entre dados coletados (BASTOS, 1994).

Mathieu e Zajac (1990) também contribuíram com os antecedentes do comprometimento ao publicarem uma revisão e meta-análise dos antecedentes do comprometimento que resumem os resultados das pesquisas realizadas nesta área, conforme representado na Figura 1, onde o autor considera correlações entre 0 e 20 como pequenas, entre 21 e 40 como moderadas e acima de 40 como altas.

Assim, os estudos acerca do comprometimento buscam examinar o quanto o comprometimento está relacionado com as características pessoais e organizacionais, bem como sua relação com variáveis como o absenteísmo, rotatividade e desempenho no emprego.

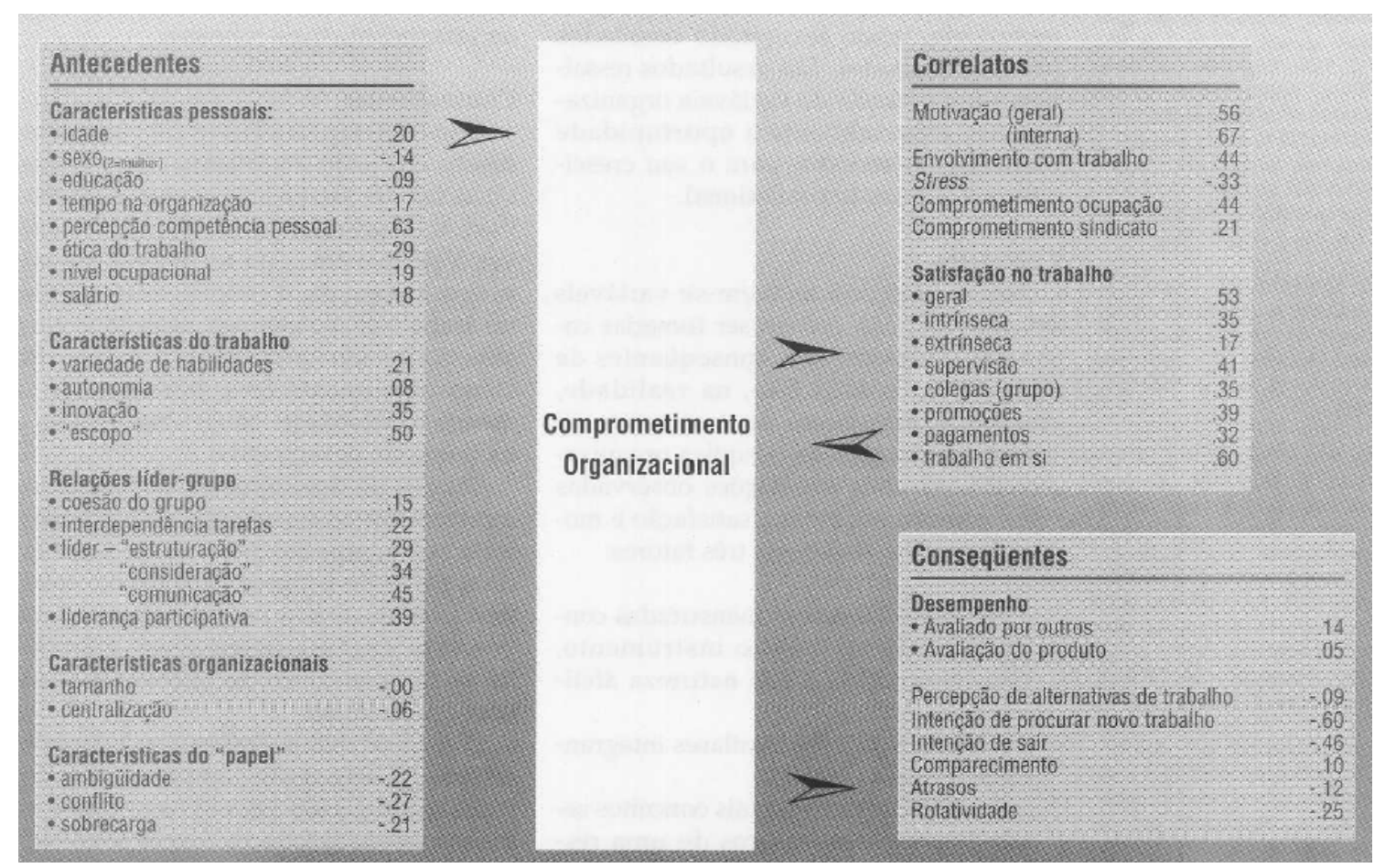

FIGURA 1: Antecedentes, Correlatos e Conseqüentes do Comprometimento

Fonte: Figura 2 Antecedentes, Correlatos e Conseqüentes do Comprometimento (correlações "corrigidas" apresentada na meta-análise de Mathieu e Zajac, 1990) de Bastos (1993, p. 61).

Para Tamayo (2001), os antecedentes do comprometimento estão ligados à variáveis individuais (idade e tempo de empresa), características do trabalho 
(tamanho, centralização, formalização), experiências no trabalho e características do papel.

A respeito destas variáveis, o autor afirma que quanto maior a idade e o tempo de empresa, mais elevado será o comprometimento. Entretanto, quanto maior o nível educacional, menor será o grau de comprometimento. Além disso, Tamayo (2001) estabelece correlações positivas entre o caráter inovador e o comprometimento.

Corroborando com as idéias de Tamayo (2001), Bastos (1993) cita que maior idade, maior tempo na organização, maior nível ocupacional e maior remuneração associam-se a um maior comprometimento. Bastos (1993) complementa a informação afirmando que o comprometimento é maior entre os homens e que tende a decrescer quanto maior o nível educacional.

Quanto às relações grupo-liderança, correlações mais elevadas de comprometimento foram encontradas no estilo participativo de gerência e na habilidade de comunicação do líder (BASTOS, 1993).

Bastos (1994) destaca outras correlações entre comprometimento e diversas variáveis citadas por inúmeros autores, conforme relatado no Quadro 2.

No que se refere aos conseqüentes do comprometimento, as pesquisas buscam relacionar as formas e graus de comprometimento com a performance do indivíduo no trabalho, bem como as relações com as variáveis rotatividade e absenteísmo. Assim, os estudos apontam que o alto grau de comprometimento leva a menor rotatividade, baixo absenteísmo e melhoria do desempenho, ressaltando que a relação comprometimento-rotatividade é mais forte em fase de início de carreira e comprometimento-absenteísmo e comprometimento-desempenho são mais fortes nas fases intermediárias e finais da carreira (BASTOS, 1993).

Ainda no âmbito dos conseqüentes, o autor afirma correlações mais expressivas com várias intenções comportamentais como desejo de deixar o emprego em busca de um novo emprego.

Acerca das formas de comprometimento, os estudos têm mostrado que quanto maior o grau de comprometimento afetivo do funcionário, maior será sua performance e quanto maior o grau de comprometimento instrumental, menos satisfatório será o desempenho deste empregado no trabalho. 
Assim, no que se refere ao comprometimento afetivo, Meyer e Allen (1997), citados por Silva (2007, p. 28), afirmam que "os indicadores de desempenho verificados em diversas amostras, sugerem que empregados com forte comprometimento afetivo serão mais valiosos para a organização do que aqueles que apresentam comprometimento afetivo fraco."

Nesse contexto, Zanelli et al. (2004) afirmam que empregados comprometidos afetivamente apresentam melhores indicadores de desempenho e ainda possuem menores taxas de rotatividade, absenteísmo e intenção de sair da empresa.

Já no enfoque do comprometimento instrumental esses autores relatam uma relação negativa do comprometimento com motivação, desempenho no trabalho e intenção de sair da empresa. Desta forma, empregados com alto grau de comprometimento instrumental tendem a ser menos motivados e a apresentarem menor nível de desempenho no trabalho.

No âmbito do comprometimento normativo, os autores afirmam que experiências individuais de socialização cultural, familiar e social anteriores à entrada na empresa, quando se internaliza a importância de ser fiel a uma dada organização; e o processo de socialização na própria empresa, na qual após a sua entrada, o trabalhador pode acreditar que é esperado dele um forte compromisso normativo.

\begin{tabular}{|l|l|}
\hline Autor & Citação \\
\hline $\begin{array}{l}\text { Luthan et al. (1987); Glisson e } \\
\text { Durik (1988); Mottaz (1998) }\end{array}$ & $\begin{array}{l}\text { As correlações entre o comprometimento e as } \\
\text { características pessoais tendem a ser reduzidas. Maior } \\
\text { comprometimento está associado com maior idade, maior } \\
\text { tempo na organização e maior remuneração. }\end{array}$ \\
\hline $\begin{array}{l}\text { Angle e Perry (1986) - Morris e } \\
\text { Scherman (1981) - Mowday et } \\
\text { al. (1982) - Dornstein e } \\
\text { Matalon (1989) }\end{array}$ & $\begin{array}{l}\text { O comprometimento entre as mulheres e entre os casados } \\
\text { (homens e mulheres) tende a decrescer quanto maior for o } \\
\text { nível educacional deles. }\end{array}$ \\
\hline $\begin{array}{l}\text { Buchnan (1974) - Kidron } \\
\text { (1978) - Blau (1987) }\end{array}$ & $\begin{array}{l}\text { O comprometimento é mais elevado entre os que aderem à } \\
\text { ética protestante do trabalho. }\end{array}$ \\
\hline Putti et al. (1989) & $\begin{array}{l}\text { O comprometimento é mais elevado entre os que aderem } \\
\text { aos valores extrínsecos. }\end{array}$ \\
\hline Mathieu \& Hamel (1989) & A descentralização afeta o comprometimento. \\
\hline Chelte \& Tausky (1987) & $\begin{array}{l}\text { O tipo de ocupação constitui um dos moderadores da } \\
\text { imensidade do comprometimento. }\end{array}$ \\
\hline Vardi et al. & $\begin{array}{l}\text { Em organizações onde há grande valorização da sua } \\
\text { missão, os trabalhadores apresentam maior } \\
\text { comprometimento normativo. }\end{array}$ \\
\hline Caldwell et AL. (1990) & $\begin{array}{l}\text { Os processos de recrutamento e seleção, aliados a um } \\
\text { sistema de valores claros, se associam a níveis mais } \\
\text { elevados de comprometimento baseados na internalização. }\end{array}$ \\
\hline
\end{tabular}




\begin{tabular}{|l|l|}
\hline Butler \& Vodanovich (1992) & $\begin{array}{l}\text { O comprometimento normativo difere do instrumental em } \\
\text { termos de valores relativos ao trabalho: trabalhadores com } \\
\text { menos tempo na organização e que sustentam um } \\
\text { comprometimento instrumental apóiam mais fortemente os } \\
\text { valores extrínsecos, e aqueles que apresentam um } \\
\text { comprometimento normativo valorizam os aspectos } \\
\text { intrínsecos do trabalho. }\end{array}$ \\
\hline Witting-Berman \& Lang (1990) & $\begin{array}{l}\text { O comprometimento afetivo apresenta uma relação } \\
\text { negativa mais forte com sintomas de stress e alienação, e } \\
\text { relações positivas com comportamentos em favor da } \\
\text { sociedade. }\end{array}$ \\
\hline Popper \& Lipshitz (1992) & $\begin{array}{l}\text { A preferência por trabalhar em organizações significativas } \\
\text { para a sociedade associa-se ao comprometimento. }\end{array}$ \\
\hline Shore \& Wayne (1993) & $\begin{array}{l}\text { O comprometimento afetivo se relaciona com a percepção } \\
\text { do suporte organizacional, revelando-se preditor do } \\
\text { comportamento de cidadania organizacional, ao contrario } \\
\text { do instrumental. }\end{array}$ \\
\hline
\end{tabular}

QUADRO 2: Citações descritas por Bastos (1994) sobre comprometimento v. variáveis diversas

Fonte: Bastos (1997), citado por Silva (2007, p. 29) 


\section{MÉTODOS E TÉCNICAS DE PESQUISA}

Para a viabilização da análise do comprometimento organizacional percebido pelos funcionários dos Correios, neste capítulo serão apresentados os aspectos metodológicos da pesquisa, de acordo com o desenvolvimento das seguintes seções: descrição geral da pesquisa; caracterização da organização ou área/setor investigado; caracterização da população e amostra; caracterização dos instrumentos de pesquisa; e descrição dos procedimentos de coleta e de análise de dados empregados.

\subsection{Tipo e descrição geral da pesquisa}

A pesquisa do comprometimento organizacional realizada na Administração Central dos Correios buscou avaliar o enfoque de comprometimento percebido pelos colaboradores da empresa.

Além da identificação do enfoque de comprometimento, a pesquisa expõe sobre as características dos funcionários e suas correlações com o comprometimento, portanto trata-se de uma pesquisa de caráter descritiva.

O processo de investigação abordou uma pesquisa de campo, quantitativa, cuja coleta dos dados se deu por meio de um questionário, já validado, que buscou identificar em qual enfoque de comprometimento o funcionário está enquadrado.

A partir dos dados e correlações encontrados, o trabalho apresentou ações que desenvolvam o comprometimento organizacional dos funcionários da empresa.

\subsection{Caracterização da organização, setor ou área}

A organização pesquisada foi a Empresa Brasileira de Correios e Telégrafos, empresa pública, onde seu único acionista é o Governo Federal. Trata-se de uma 
organização subordinada ao Ministério das Comunicações. A missão dos Correios é "oferecer soluções acessíveis e confiáveis para conectar pessoas, instituições e negócios, no Brasil e no mundo" e sua visão é "ser uma empresa de classe mundial".

A empresa possui valores focados na ética, meritocracia, respeito às pessoas, compromisso com o cliente e sustentabilidade. Sua criação, no dia 20 de março de 1969, pela Lei o․ 509, foi essencial para a reorganização do sistema postal no país. O antigo Departamento de Correios e Telégrafos (DCT) era uma entidade obsoleta que não vinha conseguindo satisfazer a nova demanda por serviços de correios no Brasil. Sua antiga infra-estrutura não era compatível com as necessidades dos usuários.

Após 1969, a Empresa evoluiu bastante em vários aspectos e passou a ser uma organização que realiza importante função de integração e de inclusão social. Nesse sentido, a empresa oferece vários programas sociais e culturais em todos os estados brasileiros e no Distrito Federal. Além disso, a empresa também é responsável pelo patrocínio de diversas atividades esportivas no cenário nacional.

$\mathrm{Na}$ década de 1980, a empresa se afirmou como instituição nacional de maior credibilidade perante a sociedade, devido à qualidade dos serviços postais por ela prestados.

Os Correios prestam inúmeros serviços e possuem um grande leque de produtos nacionais e internacionais. Entre eles, pode-se citar: telegramas, encomendas, cartas comuns e especiais e malotes.

A empresa oferece à sociedade serviços expressos, com rapidez, segurança, comodidade e com alto nível de credibilidade, como o Sedex. Este produto é um dos maiores responsáveis pela receita da empresa e possui algumas variações no que diz respeito ao tempo de entrega (urgência): Sedex comum, Sedex 10, Sedex Hoje, Sedex Mundi, e-Sedex e outros.

Atualmente, pode-se afirmar que a globalização econômica e a integração de mercados trouxeram uma grande dinamicidade ao mercado postal brasileiro e diante desse desafio, surgiu em 2009 o Plano de Diretrizes de Modernização dos Correios, elaborado pelo Grupo de Trabalho Interministerial (GTI), criado pelo Presidente da 
República. Tal Plano versa sobre políticas e ações para a modernização da empresa.

Outro assunto recente se refere à conquista do monopólio postal, em agosto de 2009, na qual o Supremo Tribunal Federal julgou improcedente a ação de quebra do monopólio postal dos Correios pela ação de apresentada em 2003 pela Associação Brasileira das Empresas de Distribuição (Abraed).

Com a manutenção do monopólio, os Correios continuarão atuando com exclusividade na captação e entrega de telegramas, cartões postais, correspondências agrupadas e cartas. Já as remessas de mercadorias, encomendas, impressos em geral continuarão sendo exploradas em regime de livre concorrência.

Com relação a sua estrutura administrativa, os Correios possuem uma Administração Central, sediada no Setor Bancário Norte, em Brasília e 28 Diretorias Regionais distribuídas nos vários estados brasileiros. A Administração Central uma é atualmente é composta pelo Conselho Fiscal, Conselho de Administração, Auditoria, Presidência, Gabinete da Presidência, Superintendência Executiva e seis Diretorias, bem como seus departamentos subordinados, como mostra o Anexo A.

Esta cúpula da empresa é composta por membros nomeados pelo Presidente da República, que dentre outras funções, fixam a orientação geral dos negócios da empresa, aprovam seu orçamento e seus planos gerais e exercem a administração superior da empresa.

O quadro de pessoal da empresa é composto por 108.808 funcionários, dos quais cerca de $85 \%$ pertencem à área operacional e 15\% à área administrativa. A Administração Central dos Correios representa um quadro de pessoal composto por 2.436 funcionários. Desse efetivo, há pesquisas realizadas pela empresa que relatam que, $56 \%$ são do sexo masculino e $70 \%$ possuem ensino superior completo.

\subsection{População e amostra}

O universo da pesquisa foram os funcionários da Administração Central dos Correios, que inclui chefes de departamento, gerentes, analistas e técnicos dos 
quarenta departamentos das áreas comercial, tecnológica, operacional, gestão de pessoas, presidência e departamentos independentes.

O quadro efetivo dos Correios conta com 108.808 funcionários, do quais cerca de $85 \%$ são carteiros e $15 \%$ estão distribuídos entre as áreas administrativas e estratégicas da Administração Central e das 28 Diretorias Regionais.

A pesquisa se limitou à Administração Central, que conta com o efetivo de 2.436 funcionários. Deste total, uma amostra permitirá tirar conclusões sobre a forma de comprometimento organizacional identificado em toda a organização.

Desta forma, o cálculo da amostra, com um nível de confiança de 95\%, margem de erro de 5\% e com o índice de 1/3 para a ocorrência da forma de comprometimento, perfaz o total de 310 questionários aplicados, conforme demonstração abaixo:

$$
n=\frac{\sigma^{2} \cdot p \cdot q \cdot N}{e^{2}(N-1)+\sigma^{2} p \cdot q} \quad n=\frac{4^{*} 33,3 * 66,6 * 2 \cdot 436}{25^{*} 2.435+4{ }^{*} 33,3 * 66,6} \quad n=310
$$

Portanto, a amostra é não probabilística, por acessibilidade e por processo bola de neve, uma vez que os funcionários foram selecionados de acordo com o grau de contato com a pesquisadora, bem como uma amostra aleatória de funcionários deu origem a outras amostras.

\subsection{Caracterização dos instrumentos de pesquisa}

$O$ instrumento de pesquisa (Anexo B) foi baseado no modelo desenvolvido por Meyer e Allen (1991), adaptado ao Brasil por Siqueira (2001, p.8), contemplando questões fechadas de escalonamento tipo Likert, que conforme relatado por Malhotra (2001), é a técnica que possui cinco alternativas que vão de concordo totalmente a discordo totalmente. 
O processo de validação empírica deste questionário resultou em índices estatísticos que atestam a viabilidade de sua aplicação: $34,8 \%$ total de variância e Alphas de Cronbach variando entre 0,86 e 0,92.

O modelo dos autores supracitados aborda um conjunto de itens do questionário pretende demonstrar o enfoque de comprometimento predominante: Afetivo, Normativo ou Instrumental. O questionário contempla 15 itens acerca do comprometimento Calculativo, 5 itens referentes ao Afetivo e 7 itens sobre 0 Normativo.

O instrumento também conta com itens objetivos a respeito de dados demográficos e funcionais dos respondentes (sexo, estado civil, escolaridade, função ocupada, escolaridade e tempo de serviço), que auxiliaram na identificação de possíveis relações de causa e efeito entre as variáveis e forneceram maior evidência quanto às correlações já identificadas por outros pesquisadores da área.

Por meio deste questionário, foi permitida possíveis associações entre os dados demográficos e a forma de comprometimento predominante nos funcionários dos Correios.

\subsection{Procedimentos de coleta e de análise de dados}

Os questionários foram entregues pessoalmente e via e-mail a funcionários de diversos departamentos, abordados aleatoriamente, com uma breve explanação escrita sobre a pesquisa. Os instrumentos foram entregues na manhã dos dias 27 e 28 de outubro, com o prazo de 48 horas para sua devolução.

Os dados obtidos pelo questionário foram organizados, tabulados e analisados por meio do software Statistical Package for the Social Sciences - SPSS versão 13 para caracterização (freqüência, média, desvio padrão e moda) e testagem das associações entre os dados demográficos e os três enfoques de comprometimento dos funcionários dos Correios. 


\section{RESULTADOS E DISCUSSÃO}

Neste capítulo são apresentados os resultados e análises da pesquisa aplicada na Administração Central dos Correios, com base nos objetivos e no referencial teórico desse trabalho.

Visando esclarecer os objetivos propostos, primeiramente serão abordados os resultados das análises estatísticas descritivas, tais como média (M), moda (Mo) e desvio-padrão (dp) dos dados demográficos e dos itens referentes a cada um dos três fatores do comprometimento organizacional. Ainda serão analisados os fatores do comprometimento e as variáveis demográficas, por meio do Teste $\mathrm{T}$ para o cálculo de diferença entre duas variáveis.

A partir da aplicação da parte II do Questionário (Apêndice A), referente aos dados demográficos, foi possível identificar que a maioria dos questionados são homens (59\%), casados $(60,3 \%)$, com nível superior completo $(50,6 \%)$, sem função $(40,3 \%)$, com uma média de 39 anos de idade e de 12 anos de empresa, conforme constatado na Tabela 1.

\begin{tabular}{|c|c|c|c|c|c|}
\hline & & Freqüência & Percentual & $\begin{array}{l}\text { Desvio } \\
\text { Padrão }\end{array}$ & Média \\
\hline \multirow[t]{2}{*}{ Sexo } & Feminino & 125 & $41,00 \%$ & & \\
\hline & Masculino & 185 & $59,00 \%$ & & \\
\hline \multirow[t]{2}{*}{ Estado Civil } & Solteiro & 123 & $39,70 \%$ & & \multirow{2}{*}{ - } \\
\hline & Casado & 187 & $60,30 \%$ & & \\
\hline \multirow[t]{5}{*}{ Escolaridade } & Ensino Médio Completo & 44 & $14,20 \%$ & & \multirow{5}{*}{ - } \\
\hline & Superior Completo & 157 & $50,60 \%$ & & \\
\hline & $\begin{array}{l}\text { Especialização } \\
\text { Completa }\end{array}$ & 95 & $30,60 \%$ & & \\
\hline & Mestrado Completo & 11 & $3,50 \%$ & & \\
\hline & Doutorado Completo & 3 & $1,00 \%$ & & \\
\hline \multirow[t]{6}{*}{ Função } & Não Possui Função & 125 & $40,30 \%$ & & \multirow{6}{*}{ - } \\
\hline & Entre Analista I e VI & 100 & $32,30 \%$ & & \\
\hline & Entre Analista VII e XII & 54 & $17,40 \%$ & & \\
\hline & Gerente Corporativo & 10 & $3,20 \%$ & & \\
\hline & Chefe de Departamento & 5 & $1,60 \%$ & & \\
\hline & Outros & 16 & $5,20 \%$ & & \\
\hline \multicolumn{2}{|l|}{ Idade } & - & - & 9,34 & 39,19 \\
\hline \multicolumn{2}{|c|}{ Tempo de Serviço } & - & - & 10,9 & 12,21 \\
\hline
\end{tabular}


A partir da aplicação da parte I do Questionário (Apêndice A), que abordou 27 itens, com questões associadas a um escala do tipo Likert de 5 pontos (1=discordo totalmente até $5=$ concordo totalmente) possibilitou-se a obtenção do enfoque de comprometimento organizacional predominante na Administração Central da empresa.

Diante da escala Likert, valores entre 1 a 2,49 são considerados baixos; valores entre 2,5 a 3,49 são considerados moderados e valores superiores a 3,5 são considerados altos.

No que consiste ao desvio padrão, medida indicadora de discrepâncias no momento da marcação da resposta, ou seja, que acusa heterogeneidade do grupo pesquisado; é denotado como presença de divergência entre respostas os desvios padrões elevados $(d p>0,90)$ e homogeneidade de respostas para desvios padrões baixos $(\mathrm{dp}<0,90)$.

A Tabela 2 consiste da apresentação dos itens 1 a 15, que compõe o comprometimento calculativo, no qual é possível identificar uma média geral de 2,55 e desvio padrão geral de 0,69 .

Percebe-se que a tendência de resposta para os itens referentes ao comprometimento calculativo foi de discordância $(\mathrm{Mo}=2)$, logo a média geral $(M=2,55)$ representa um grau de comprometimento calculativo moderado, com um baixo desvio padrão $(\mathrm{dp}=0,69)$.

Vale destacar que os itens 7 e 13, que atingiram melhores avaliações ( $M=2,99$ e $M=3,50$ ) se referem a estabilidade e aos benefícios, respectivamente. Assim, inferese que os funcionários estão relativamente satisfeitos com os benefícios oferecidos pela empresa e se mantém ligados a ela devido à estabilidade no emprego.

A percepção dos funcionários quanto ao item 10 , relacionado às dificuldades para ganhar um salário tão bom quanto ao que o funcionário possui em um possível pedido de demissão, foi o item que apresentou maior dispersão de respostas, com o desvio padrão ( $\mathrm{dp}=1,15)$, o que se infere dizer que não há um consenso entre os respondentes a respeito desse item. 


\begin{tabular}{|c|c|c|c|}
\hline Itens do Comprometimento Calculativo & Média & Moda & $\begin{array}{l}\text { Desvio } \\
\text { Padrão }\end{array}$ \\
\hline $\begin{array}{l}\text { Eu perderia o prestígio que tenho hoje por ser empregado dessa } \\
\text { empresa. }\end{array}$ & 2,01 & 1 & 1,06 \\
\hline 2. Eu estaria prejudicando minha vida profissional. & 2,20 & 2 & 1,03 \\
\hline $\begin{array}{l}\text { 3. Eu teria mais coisas a perder do que ganhar com esse pedido de } \\
\text { demissão. }\end{array}$ & 2,84 & 2 & 1,13 \\
\hline $\begin{array}{l}\text { 4. Eu estaria desperdiçando todo o tempo que já dediquei a essa } \\
\text { empresa. }\end{array}$ & 2,46 & 2 & 1,13 \\
\hline 5. Eu deixaria para trás tudo que já investi nessa empresa. & 2,71 & 2 & 1,13 \\
\hline 6. Eu estaria jogando fora todo o esforço que fiz para aprender. & 2,18 & 2 & 1,08 \\
\hline $\begin{array}{l}\text { 7. Eu perderia a estabilidade no emprego que tenho hoje nessa } \\
\text { empresa. }\end{array}$ & 2,99 & 4 & 1,21 \\
\hline $\begin{array}{l}\text { 8u demoraria para conseguir ser tão respeitado em outra empresa } \\
\text { como sou hoje dentro da empresa. }\end{array}$ & 2,49 & 2 & 1,15 \\
\hline $\begin{array}{l}\text { 9. Eu jogaria fora todos os esforços que fiz para chegar onde cheguei } \\
\text { dentro dessa empresa. }\end{array}$ & 2,50 & 2 & 1,06 \\
\hline $\begin{array}{l}\text { 10. Eu teria dificuldades para ganhar um salário tão bom quanto o que } \\
\text { tenho hoje. }\end{array}$ & 2,32 & 2 & 1,15 \\
\hline $\begin{array}{l}\text { 11. Eu teria dificuldade para conseguir outro cargo que me desse o } \\
\text { mesmo prestígio que tenho com o meu cargo atual. }\end{array}$ & 2,29 & 2 & 1,09 \\
\hline $\begin{array}{l}\text { 12. Eu demoraria para encontrar em outra empresa pessoas tão amigas } \\
\text { quanto as que tenho hoje entre meus colegas de trabalho. }\end{array}$ & 2,68 & 2 & 1,08 \\
\hline 13. Eu deixaria de receber vários benefícios que essa empresa oferece. & 3,50 & 4 & 1,07 \\
\hline $\begin{array}{l}\text { 14. Eu perderia a liberdade que tenho de realizar meu trabalho dentro } \\
\text { dessa empresa. }\end{array}$ & 2,80 & 3 & 1,07 \\
\hline 15. Eu levaria muito tempo para me acostumar com um novo trabalho. & 2,22 & 2 & 0,95 \\
\hline Médias Globais & 2,55 & 2 & 0,69 \\
\hline
\end{tabular}

Tabela 2: Dados do Comprometimento Calculativo

Fonte: Dados de pesquisa

A Tabela 3 apresenta os itens 16 a 20, que se relacionam ao comprometimento afetivo. Dentre os enfoques de comprometimento estudados, o Afetivo foi o que obteve a maior média e desvio padrão $(M=3,11$ e $\mathrm{dp}=0,90)$.

Apesar de ter apresentado a maior média, considerada moderada, o comprometimento afetivo percebido pelos funcionários pesquisados não foi consensual, visto que o desvio padrão foi alto.

Os itens 19 e 20, referentes ao comprometimento afetivo tiveram avaliações superiores aos demais itens do questionário $(M=3,41$ e $M=3,43)$. Essa pontuação permite afirmar que os funcionários possuem o sentimento de orgulho e interesse pela empresa em que trabalham. Tais constatações podem ser explicadas devido ao reconhecimento dos Correios, eleito recentemente como uma das cinco instituições 
mais confiáveis pelos brasileiros, o que remete aos próprios funcionários o sentimento de orgulho em trabalhar nessa instituição.

O item com a menor pontuação foi o $16(\mathrm{M}=2,76)$, relativo ao baixo entusiasmo que o funcionário possui pela empresa, podendo ser explicado devido à recente reestruturação na Administração Central e constantes mudanças políticas na direção da empresa, que afetam os funcionários. Ou seja, apesar do orgulho e sentimento de interesse demonstrado pelos funcionários, há fatores inerentes à administração que os levam a um baixo índice de entusiasmo.

\begin{tabular}{lccc}
\hline Itens do Comprometimento Afetivo & Média & Moda & $\begin{array}{c}\text { Desvio } \\
\text { Padrão }\end{array}$ \\
\hline 16. Animado com ela. & 2,91 & 3,00 & 1,06 \\
17. Contente com ela. & 3,04 & 4,00 & 1,05 \\
18. Entusiasmado com ela. & 2,76 & 3,00 & 1,04 \\
19. Interessado por ela. & 3,41 & 4,00 & 1,08 \\
20. Orgulhoso dela. & 3,43 & 4,00 & 1,10 \\
Médias Globais & $\mathbf{3 , 1 1}$ & $\mathbf{4 , 0 0}$ & $\mathbf{0 , 9 0}$ \\
\hline
\end{tabular}

Tabela 3: Dados do Comprometimento Afetivo

Fonte: Dados de pesquisa

O terceiro enfoque de comprometimento pesquisado é o Normativo, que apresentou média geral 2,25 e desvio padrão geral 0,66, conforme representado na Tabela 4. Diante desta pontuação, ao comparar os enfoques de comprometimento, percebe-se que o Normativo possui média e desvio padrão inferiores.

Os itens do comprometimento normativo que apresentaram menores avaliações foram os itens 22 e $23(\mathrm{M}=1,77$ e $\mathrm{M}=1,65)$, dizem respeito à desonestidade ao sair da empresa e a obrigação em continuar trabalhando na empresa. Já o item mais expressivo dessa categoria, item 24 , se refere ao que a empresa fez pelo funcionário no passado. Assim, os funcionários reconhecem o investimento que a empresa fez por eles e continuam trabalhando nos Correios devido a esse reconhecimento. No entanto, não se vêem obrigados a continuar na empresa somente por esse motivo.

\begin{tabular}{|c|c|c|c|c|}
\hline \multicolumn{2}{|c|}{ Itens do Comprometimento Normativo } & \multirow{2}{*}{$\frac{\text { Média }}{1,97}$} & \multirow{2}{*}{$\frac{\text { Moda }}{2}$} & \multirow{2}{*}{$\begin{array}{c}\begin{array}{c}\text { Desvio } \\
\text { Padrão }\end{array} \\
0,96\end{array}$} \\
\hline 21. & $\begin{array}{l}\text { Eu seria injusto com essa empresa se pedisse demissão agora e } \\
\text { fosse trabalhar em outra empresa. }\end{array}$ & & & \\
\hline 22. & $\begin{array}{l}\text { Seria desonesto de minha parte ir trabalhar para outra empresa } \\
\text { agora. }\end{array}$ & 1,77 & 2 & 0,80 \\
\hline 23. & É minha obrigação continuar trabalhando para essa empresa. & 1,65 & 1 & 0,87 \\
\hline 24. & Nesse momento, essa empresa precisa de meus serviços. & 2,81 & 3 & 1,17 \\
\hline
\end{tabular}


25. É a gratidão por essa empresa que me mantém ligado a ela. $\quad \begin{array}{rrr}2,29 & 2 & 1,11\end{array}$

26. Essa empresa já fez muito por mim no passado. $\quad 2,89 \quad \begin{array}{lll}3 & 1,21\end{array}$

27. Continuar trabalhando nessa empresa é uma forma de retribuir o $\begin{array}{llll}2,37 & 2 & 0,99\end{array}$

\begin{tabular}{llll}
\hline Médias Globais & 2,25 & 2 & 0,66 \\
\hline
\end{tabular}

Tabela 4: Dados do Comprometimento Normativo

Fonte: Dados de pesquisa

A partir da análise fragmentada dos itens da parte I do Questionário, pode-se verificar na Tabela 5 a maior média nos itens referentes ao comprometimento afetivo ( $M=3,11$ e $d p=0.90)$, seguido do comprometimento calculativo $(M=2,55$ e $d p=0,69)$ e o comprometimento normativo $(\mathrm{M}=2,25$ e $\mathrm{dp}=0,66)$. Portanto, o enfoque de comprometimento organizacional predominante na Administração Central dos Correios é o comprometimento afetivo.

Segundo Naves (2003) e Zanelli (2004), os funcionários afetivamente comprometidos tendem a contribuir de forma positiva para a empresa tendo em vista que, assim, manifestam um desejo de permanecer como membro da organização e exercem um esforço considerável em favor dela. Assim, os funcionários pesquisados estão expressando seu desejo de permanecerem na organização.

Ao se reportar a resposta sobre qual é o enfoque de comprometimento organizacional predominante nos Correios, obtém-se que a base de comprometimento mais evidente é a afetiva. No entanto não é única e exclusiva, visto que é sustentada pelos outros enfoques calculativo e normativo, em menores escores. Portanto, o apego às normas e às compensações que o emprego nos Correios oferece também são sentimentos constatados pelos funcionários da Empresa.

\begin{tabular}{lrrr}
\hline Enfoques do Comprometimento Organizacional & \multicolumn{1}{c}{ Média } & \multicolumn{1}{c}{ Moda } & \multicolumn{2}{c}{ Pesvio } \\
\hline Compromo
\end{tabular}

Tabela 5: Análise descritiva dos Enfoques do Comprometimento Organizacional

Fonte: Dados de pesquisa

Com o objetivo de investigar variações de comprometimento com relação às características funcionais e pessoais dos entrevistados, as Tabelas 6 e 7 apresentam os resultados do Teste $T$, com nível de significância $<0,05$. Assim, foram reunidos dois grupos de cada variável demográfica que possibilitaram identificar as 
diferenças entre grupos nos enfoques do comprometimento. A definição da média de corte entre os grupos de cada variável demográfica foi baseada nas médias globais apresentadas anteriormente.

Pode-se constatar na Tabela 6 que, no quesito sexo, as médias do comprometimento organizacional apresentaram maiores índices para o sexo masculino. Apesar da maior média $(M=3,23)$ estar centrada no comprometimento afetivo masculino, nota-se que a maior diferença entre os sexos se referiu ao comprometimento calculativo, com o grau de significância menor que 0,01, ou seja, a diferença entre a média de respostas da categoria sexo do comprometimento calculativo foi significativa $(p<0,01)$. Assim, infere-se que, os homens tendem a ponderar se tempo, o esforço dedicado e o dinheiro recebido compensam continuar trabalhando na organização ou abandoná-la. Na análise aprofundada dos itens, os resultados mostram ainda que os homens possuem maior receio em perder liberdade, retribuições e investimentos profissionais do que as mulheres.

Esse comportamento pode ser explicado devido ao sólido posicionamento do homem no mercado, enquanto as mulheres ainda estão conquistando este espaço em busca de boas recompensas profissionais seja nos Correios ou em outra instituição.

No quesito sexo, vale ressaltar que o grau de significância registrado no comprometimento afetivo $(p<0,05)$ é expressivo, o que conclui afirmar que os questionados do sexo masculino são mais comprometidos afetivamente, que as mulheres.

De forma geral, os homens que participaram da pesquisa relataram médias de comprometimento maiores que as mulheres, o que confirma a hipótese de Bastos (1993) ao relatar que o comprometimento é maior entre os homens.

Nas categorias referentes ao estado civil e escolaridade, embora Tamayo (2001) afirme que quanto maior o nível educacional, menor será o grau de comprometimento; os níveis de significância da pesquisa são todos superiores a 0,05, indicando não haver diferenças significativas entre as percepções de casados e solteiros; e escolaridade até o nível superior e acima deste.

O dado demográfico relacionado à função ocupada demonstrou níveis de significância superiores nos comprometimentos calculativo e normativo, com $p<0,01$. 
Assim, no que se refere ao comprometimento calculativo, os funcionários com menores funções se mostraram mais comprometidos quando comparados aos que possuem maiores funções. Por outro lado, os funcionários com funções mais elevadas apresentaram maiores médias de comprometimento normativo.

Diante do exposto, infere-se que os funcionários com funções até Analista VI, tendem a avaliar melhor as perdas sociais, de investimentos feito na organização, de retribuições funcionais e profissionais que sofreriam se saíssem da empresa, fatores estes inerentes ao comprometimento calculativo. Desse comportamento infere-se que os colaboradores com menores funções se comprometem mais, pois ainda vislumbram a possibilidade de crescimento na empresa.

Os quesitos tempo de serviço e idade apresentaram altos níveis de significância $\mathrm{p}<0,01$ em todos os tipos de comprometimento quando foram calculadas as diferenças entre médias. Ressalta-se que para a categoria tempo de serviço, 0 número de corte foi de 12 anos de empresa e na categoria idade, o número de corte foi de 39 anos de idade.

Da Tabela 6 pode-se verificar que é significativo que os colaboradores com tempo de empresa menor que 12 anos e com menos de 39 anos idade possuem maior nível de comprometimento calculativo, afetivo e normativo. Assim, infere-se que os colaboradores mais novos e com menor tempo de empresa são mais engajados e motivados no trabalho, a fim de conquistarem reconhecimento, respeito e ascensão profissional na empresa; espaço este já conquistado por aqueles com idade acima de 39 anos e com mais de 12 anos de empresa.

Nesse contexto, Medeiros e Enders (1998) afirmam que manter os funcionários dedicados, engajados e empáticos com a organização é uma das grandes preocupações das organizações.

Ao contrário do que afirmam Bastos (1993) e Tamayo (2001), que quanto maior a idade e o tempo de empresa, mais elevado será o comprometimento do colaborador, a pesquisa revelou, por meio do Teste $\mathrm{T}$, que essa constatação não ocorre na pesquisa realizada. 


\begin{tabular}{|c|c|c|c|c|c|c|c|c|}
\hline & & \multirow[b]{2}{*}{$\mathrm{N}$} & \multicolumn{2}{|c|}{ Calculativo } & \multicolumn{2}{|c|}{ Afetivo } & \multicolumn{2}{|c|}{ Normativo } \\
\hline & & & Média & $\begin{array}{l}\text { Desvio } \\
\text { Padrão }\end{array}$ & Média & $\begin{array}{l}\text { Desvio } \\
\text { Padrão }\end{array}$ & Média & $\begin{array}{l}\text { Desvio } \\
\text { Padrão }\end{array}$ \\
\hline \multirow{2}{*}{ Sexo } & Feminino & 125 & 2,32 & 0,60 & 2,94 & 0,86 & 2,17 & 0,68 \\
\hline & Masculino & 185 & 2,71 & 0,71 & 3,24 & 0,93 & 2,31 & 0,64 \\
\hline \multirow{2}{*}{ Estado Civil } & Solteiro & 123 & 2,55 & 0,67 & 2,98 & 0,85 & 2,38 & 0,64 \\
\hline & Casado & 187 & 2,55 & 0,71 & 3,20 & 0,93 & 2,17 & 0,67 \\
\hline \multirow{2}{*}{$\begin{array}{l}\text { Função } \\
\text { Ocupada }\end{array}$} & $\begin{array}{l}\text { Até Analista } \\
\mathrm{VI}\end{array}$ & 185 & 2,68 & 0,71 & 3,23 & 0,94 & 2,36 & 0,68 \\
\hline & $\begin{array}{l}\text { Acima de } \\
\text { Analista VI }\end{array}$ & 125 & 2,35 & 0,61 & 2,94 & 0,84 & 2,10 & 0,60 \\
\hline \multirow{2}{*}{$\begin{array}{l}\text { Tempo de } \\
\text { Serviço }\end{array}$} & Até 12 anos & 121 & 2,85 & 0,73 & 3,41 & 0,83 & 2,48 & 0,70 \\
\hline & $\begin{array}{l}\text { Acima de } 12 \\
\text { anos }\end{array}$ & 189 & 2,36 & 0,59 & 2,93 & 0,91 & 2,11 & 0,59 \\
\hline \multirow[b]{2}{*}{ Idade } & Até 39 anos & 154 & 2,74 & 0,73 & 3,28 & 0,90 & 2,39 & 0,65 \\
\hline & $\begin{array}{l}\text { Acima de } 39 \\
\text { anos }\end{array}$ & 156 & 2,36 & 0,59 & 2,95 & 0,88 & 2,12 & 0,65 \\
\hline \multirow[b]{2}{*}{ Escolaridade } & $\begin{array}{l}\text { Até Nível } \\
\text { Superior }\end{array}$ & 266 & 2,55 & 0,70 & 3,10 & 0,91 & 2,27 & 0,64 \\
\hline & $\begin{array}{l}\text { Acima de } \\
\text { Nível } \\
\text { Superior }\end{array}$ & 44 & 2,57 & 0,66 & 3,21 & 0,93 & 2,16 & 0,76 \\
\hline
\end{tabular}

Tabela 6:Teste $T$ de diferença entre as médias do comprometimento $\mathrm{x}$ variáveis demográficas Fonte: Dados de pesquisa

\begin{tabular}{lllccc}
\hline $\begin{array}{l}\text { Dados } \\
\text { Demográficos }\end{array}$ & Comprometimento & $\begin{array}{l}\text { Comparação } \\
\text { Variância }\end{array}$ & $\mathbf{t}$ & DF & $\begin{array}{c}\text { Sig. (2- } \\
\text { tailed) }\end{array}$ \\
\hline Sexo & Calculativo & Assumida & $-5,123$ & 308 & 0 \\
& & Não assumida & $-5,275$ & 295,563 & 0 \\
Sexo & Afetivo & Assumida & $-2,823$ & 308 & 0,005 \\
& & Não assumida & $-2,863$ & 283,847 & 0,005 \\
Sexo & Normativo & Assumida & $-1,784$ & 308 & 0,075 \\
& & Não assumida & $-1,763$ & 259,968 & 0,079 \\
Estado Civil & Calculativo & Assumida & $-0,055$ & 308 & 0,956 \\
& & Não assumida & $-0,056$ & 269,319 & 0,956 \\
Estado Civil & Afetivo & Assumida & $-2,119$ & 308 & 0,035 \\
& & Não assumida & $-2,16$ & 277,562 & 0,032 \\
Estado Civil & Normativo & Assumida & 2,676 & 308 & 0,008 \\
& & Não assumida & 2,704 & 270,245 & 0,007 \\
Função & Calculativo & Assumida & 4,241 & 308 & 0 \\
& & Não assumida & 4,37 & 291,102 & 0 \\
Função & Afetivo & Assumida & 2,773 & 308 & 0,006
\end{tabular}




\begin{tabular}{lllccc} 
& & Não assumida & 2,835 & 285,235 & 0,005 \\
Função & Normativo & Assumida & 3,452 & 308 & 0,001 \\
& & Não assumida & 3,544 & 288,567 & 0 \\
Tempo de Serviço & Calculativo & Assumida & 6,581 & 308 & 0 \\
& & Não assumida & 6,281 & 216,768 & 0 \\
\multirow{2}{*}{ Tempo de Serviço } & Afetivo & Assumida & 4,655 & 308 & 0 \\
& & Não assumida & 4,744 & 271,648 & 0 \\
Tempo de Serviço & \multirow{2}{*}{ Normativo } & Assumida & 5,045 & 308 & 0 \\
& & Não assumida & 4,871 & 226,012 & 0 \\
Idade & Calculativo & Assumida & 4,968 & 308 & 0 \\
& & Não assumida & 4,961 & 293,602 & 0 \\
Idade & Afetivo & Assumida & 3,293 & 308 & 0,001 \\
& & Não assumida & 3,293 & 307,614 & 0,001 \\
Idade & Normativo & Assumida & 3,565 & 308 & 0 \\
& & Não assumida & 3,566 & 307,986 & 0 \\
Escolaridade & Calculativo & Assumida & $-0,222$ & 308 & 0,824 \\
& & Não assumida & $-0,231$ & 59,964 & 0,818 \\
Escolaridade & Afetivo & Assumida & $-0,733$ & 308 & 0,464 \\
& & Não assumida & $-0,718$ & 57,265 & 0,476 \\
Escolaridade & Normativo & Assumida & 1,056 & 308 & 0,292 \\
& & Não assumida & 0,94 & 53,757 & 0,352 \\
\hline
\end{tabular}

Tabela 7: Teste T de Significância do comprometimento $\mathrm{x}$ variáveis demográficas

Fonte: Dados de pesquisa 


\section{CONCLUSÕES E RECOMEDAÇÕES}

O presente trabalho teve como objetivo verificar o enfoque de comprometimento organizacional predominante nos funcionários da Administração Central dos Correios, e possíveis relações entre variáveis demográficas e funcionais desses com o comprometimento organizacional.

Para viabilizar o estudo, foi realizada uma revisão teórica sobre o tema que forneceu subsídios para a pesquisa descritiva realizada com os 310 funcionários da ECT.

Pode-se considerar que o objetivo foi alcançado visto que foi possível identificar que o comprometimento organizacional predominante é o Afetivo, que apresentou maior média e também foi possível verificar que há uma diferenciação de percepção do comprometimento de acordo com dados pessoais e funcionais dos pesquisados.

Vale ressaltar que, além do comprometimento organizacional afetivo, a pesquisa também identificou a presença do Normativo e Calculativo.

Acerca dos três principais enfoques do comprometimento, Hersey e Blanchard (1982 apud Silva, 2007) afirma que a pessoa sadia é aquela que tem uma personalidade que mantém equilíbrio entre os estados de ego inerentes ao comprometimento afetivo, calculativo e normativo.

Tendo em vista que não foi identificado comprometimento com médias equilibradas entre os três enfoques, sugerem-se algumas recomendações acerca das políticas de gestão de pessoas na tentativa de promover a elevação do grau de comprometimento geral dos funcionários da empresa.

Segundo Bandeiras, Marques e Veiga (2000), as políticas de recursos humanos influenciam, de certa forma, o envolvimento dos empregados, sendo que esse vínculo pode assumir inúmeras facetas.

$\mathrm{Na}$ análise das variáveis demográficas, os pontos identificados como críticos da pesquisa se referem à média de comprometimento dos funcionários que possuem maior tempo de serviço $(M=2,11$ e $d p=0,59)$ e escolaridade maior que o nível superior $(\mathrm{M}=2,16$ e $\mathrm{dp}=0,76)$, principalmente no que tange ao comprometimento normativo. 
$\mathrm{Na}$ análise dos enfoques de comprometimento, o Normativo $(\mathrm{M}=2,25$ e dp=0,66) e o Calculativo $(\mathrm{M}=2,55$ e $\mathrm{dp}=0,69)$ apresentam baixos índices de comprometimento.

Diante das estatísticas apresentadas, recomendam-se mudanças e melhorias nas políticas e práticas de gestão de pessoas, com atenção especial para o tempo de serviço e grau de escolaridade do funcionário. Assim, os colaboradores que apresentaram os menores índices de comprometimento teriam definições claras acerca dos benefícios que as variáveis: tempo de serviço e nível de escolaridade poderiam proporcionar.

Segundo Naves e Coleta (2003), o comprometimento normativo pode ser percebido quando há benefícios e experiências que induzem a sentir vontade de agir reciprocamente. Assim, políticas de recursos humanos como ações de valorização dos funcionários com mais de 12 anos de empresa e com mestrado e doutorado, poderiam elevar o grau de tal comprometimento, que se mostrou com baixa avaliação.

Para uma clara avaliação acerca das melhores políticas de recursos humanos que desencadeiam altos níveis de comprometimento sugere-se uma análise aprofundada, com entrevistas individuais e grupos focais, visando identificar mudanças e melhorias nas políticas e práticas de gestão de pessoas para o aumento do grau de comprometimento dos funcionários.

Concluindo, o trabalho realizado apurou que existem aspectos do comprometimento que podem ser melhorados mediante adoção de ações de recursos humanos que visem aumentar o grau de comprometimento dos empregados. Portanto, faz-se necessária que a realização de tal pesquisa seja uma frequente na ECT, de modo a monitorar o grau de comprometimento dos empregados em relação às políticas de pessoal adotadas pela empresa, buscando assim, com colaboradores mais comprometidos, ser uma empresa mais fortalecida perante o mercado. 


\section{REFERÊNCIAS}

BANDEIRA, M. L.; MARQUES, A. L.; VEIGA R. T. As Dimensões Múltiplas do Comprometimento Organizacional: um Estudo na ECT/MG. Revista de Administração Contemporânea, v. 4, n. 2, Mai./Ago. 2000: 133-157.

BARBETTA, P. A. Estatística Aplicada às Ciências Sociais. Porto Alegre: Ed. UFSC, 2005.

BASTOS, A. V. B.; BRANDÃO, M. G. A.; PINHO, A. P. M. Comprometimento Organizacional: uma Análise do Conceito Expresso por Servidores Universitários no Cotidiano de Trabalho, Revista de Administração Contemporânea, v. 1, n. 2, Maio;Ago. 1997: 97-120.

BASTOS, A. V. B; CORREA, N. C. N.; LIRA, S. B; Padrões de Comprometimento com a Profissão e a Organização: O Impacto de Fatores Pessoais e da Natureza do Trabalho. CNPQ

BASTOS, A. V. B. Comprometimento no Trabalho: Contextos em Mudança e os Rumos da Pesquisa Neste Domínio. Encontro Anual da ANPAD. 1998. Disponível em:<http://www.anpad.org.br/login.php?cod_edicao_subsecao=53\&cod_evento_edic ao=2\&cod_edicao_trabalho=3656> Acesso em 15/08/2009.

BASTOS, A. V. B. Comprometimento no Trabalho: os caminhos da pesquisa e os seus desafios metodológicos. Em, Tamayo, A., Borges-Andrade, J. E. e Codo, W., Trabalho, Organizações e Cultura. São Paulo: Cooperativa de Autores Associados, p. 105-127, 1996.

BASTOS, A. V. B., Comprometimento Organizacional: um Balanço dos Resultados e Desafios que Cercam essa Tradição de Pesquisa, Revista de Administração de Empresas, São Paulo, 33(3):55-64, 1993.

BORGES, L. O et al, Comprometimento no Trabalho e sua Sustentação na Cultura e no Contexto Organizacional, RAE-eletrônica, v. 3, n. 1, Art. 8, jan./jun 2004.

CORREIOS. Brasília, 2009. Disponível em: < http://www.correios.com.br/institucional/conheca correios/conheca.cfm>, acesso em 18/09/09. 
FLAUZINO, D. P.; BORGES-ANDRADE, J. E.; Comprometimento de servidores públicos e alcance de missões organizacionais, Revista de Administração Pública, Rio de Janeiro, 42(2):253-73, Mar./Abr. 2008

MEDEIROS, C. A. F; EDERS, W. T. Validação do Modelo de Conceituação de Três Componentes do Comprometimento Organizacional (Meyer e Allen, 1991), Revista de Administração Contemporânea, v. 2, n. 3, Set./Dez. 1998: 67-87.

MEDEIROS, C. A. F et al, Comprometimento Organizacional: o Estado da Arte da Pesquisa no Brasil, Revista de Administração Contemporânea, v. 7, n. 4, Out./Dez. 2003: 187-209.

MORAES, F. M. M.; GODOI, C. K; BATISTA, M. A. Comprometimento Organizacional: uma Pesquisa Documental sobre a Produção Científica Brasileira de 1994 a 2003, Revista de Ciências da Administração, v. 6, n 12, Jul./Dez., 2004.

MULLER, M. et al, Comprometimento Organizacional: um Estudo de Caso no Supermercado "Beta", Revista Gestão Industrial, v. 01, n. 04, p. 511-518, 2005.

NAVES, E. M. R.; COLETA, M. F. D. Cultura e Comprometimento Organizacional em Empresas Hoteleiras, Revista de Administração Contemporânea, Edição Especial 2003: 205-222.

REGO, A.; SOUTO, S. Comprometimento Organizacional em organizações Autentizóticas: um Estudo Luso-brasileiro, RAE-eletrônica, v. 44, n. 3, Jun./Set. 2004.

REGO, A; CUNHA, M. P. Espiritualidade nas Organizações e Comprometimento Organizacional, RAE-eletrônica, v. 6, n. 2, Art. 12, jul./dez. 2007.

REGO, A. Comprometimento Afectivo dos membros Organizacionais: o Papel das percepções de Justiça; Revista de Administração Contemporânea, v. 6, n. 2, Maio/Ago. 2000: 209-241.

REGO, A. Comprometimento Organizacional e Ausência Psicológica - Afinal, Quantas Dimensões?, RAE, v3 43, n. 4, Out./Dez., 2003.

SILVA, M. C. C.; Avaliação do Comprometimento dos Servidores de uma Instituição Pública Federal de Pesquisa: o Caso dos Pesquisadores do IPEN, Tese de Mestrado, Universidade de São Paulo, 2007. 
TAMAYO, A. et al, Prioridades Axiológicas e Comprometimento Organizacional, Psicologia: Teoria e Pesquisa, v. 17, n. 1, p. 27-35, 2001.

VERGARA, C. S. Projetos e Relatórios de Pesquisa em Administração, $7^{a}$ Ed. São Paulo: Ed. Atlas S.A., 2007

ZANELLI, J. C.; BORGES-ANDRADE, J. E.; BASTOS, A. V. B. \& cols. Psicologia, Organizações e Trabalho no Brasil. Porto Alegre: Artmed, 2004. 
ANEXOS

\section{Anexo A: Organograma da Administração Central dos Correios}

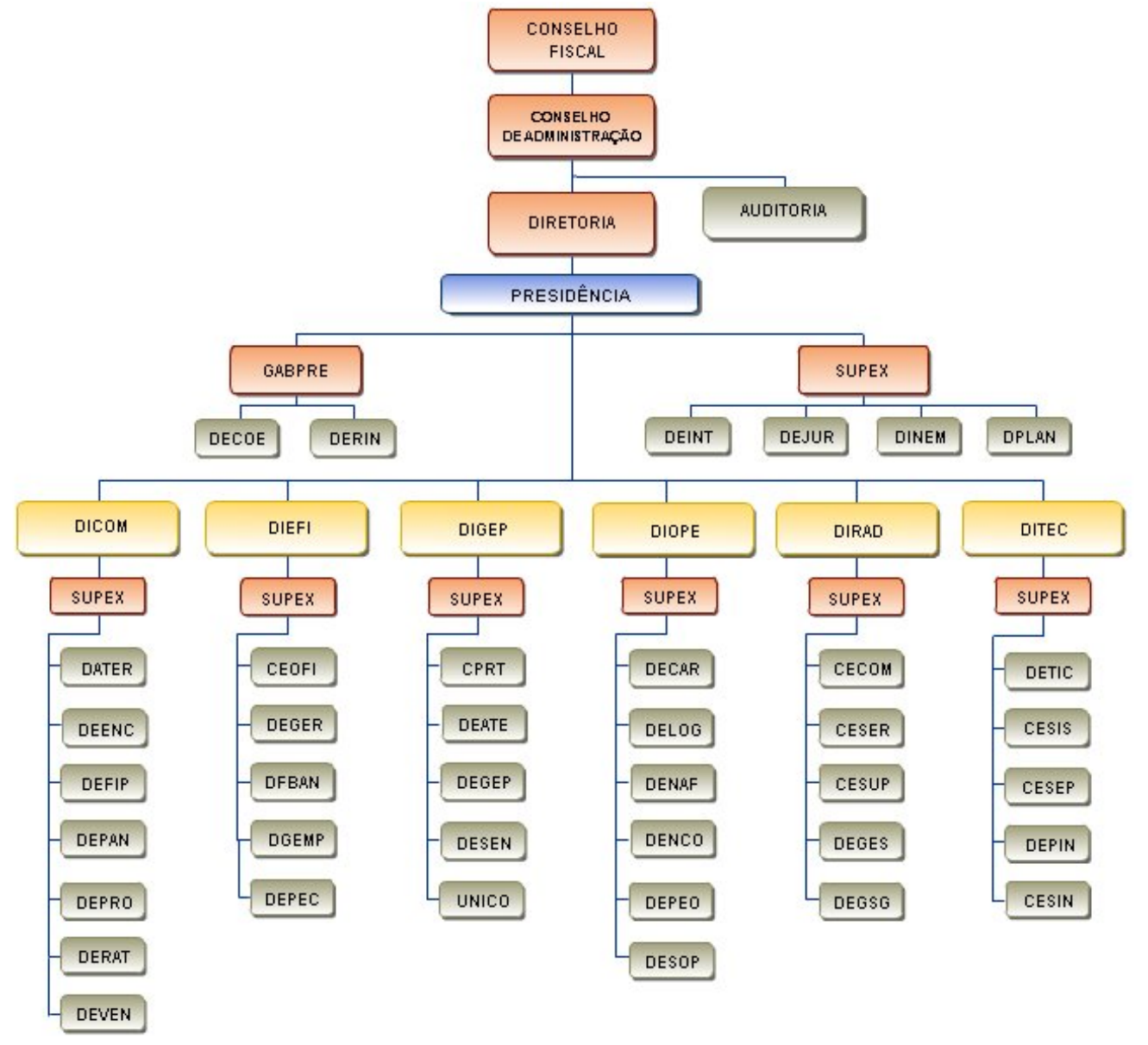




\section{Anexo B: Questionário}

Prezado (a) colaborador (a),

Sou aluna do curso de Administração da Universidade de Brasília e meu trabalho de conclusão de curso consiste em uma pesquisa sobre o comprometimento organizacional percebido por funcionários da Administração Central dos Correios.

Neste sentido, solicito sua colaboração para responder ao questionário anexo. Há 27 afirmativas para as quais você deve assinalar um número entre " 1 " e " 5 ", sendo que quanto mais próxima de um for a sua resposta, mais você discorda e quanto mais próxima de cinco a sua resposta, mais você concorda com a afirmativa.

No final do questionário peço informações sobre alguns de seus dados biográficos e funcionais, que serão utilizados apenas para verificação de possíveis tendências de respostas em razão das características de grupos de participantes da pesquisa.

Sua participação é voluntária e seu nome não será divulgado. Os dados serão analisados de forma agregada, de modo a não associar a indivíduos de forma específica. Não existem respostas certas ou erradas. O que importa é sua percepção a respeito de cada afirmativa.

Peço a gentileza de responder ao questionário, se possível, em até 48 horas, prazo em que serão recolhidos.

Agradeço antecipadamente sua participação.

Natália Fernandes Camargo

nataliacamargo@correios.com.br

3426-1460 


\title{
QUESTIONÁRIO
}

\section{PARTE I - COMPROMETIMENTO}

Considerando a organização em que você trabalha, responda os 27 itens de acordo com o quanto você concorda com cada uma das afirmativas conforme a escala abaixo.

\begin{tabular}{|c|c|c|c|c|}
\hline 1 & 2 & 3 & 4 & 5 \\
\hline $\begin{array}{c}\text { Discordo } \\
\text { totalmente }\end{array}$ & Discordo & $\begin{array}{c}\text { Não concordo } \\
\text { Nem discordo }\end{array}$ & Concordo & $\begin{array}{c}\text { Concordo } \\
\text { totalmente }\end{array}$ \\
\hline
\end{tabular}

Pedir demissão da empresa onde eu trabalho e ir para outra instituição não valeria a pena porque...

1 Eu perderia o prestígio que tenho hoje por ser empregado dessa empresa.

2 Eu estaria prejudicando minha vida profissional.

3 Eu teria mais coisas a perder do que ganhar com esse pedido de demissão.

4 Eu estaria desperdiçando todo o tempo que já dediquei a essa empresa.

5 Eu deixaria para trás tudo que já investi nessa empresa.

6 Eu estaria jogando fora todo o esforço que fiz para aprender.

7 Eu perderia a estabilidade no emprego que tenho hoje nessa empresa.

Eu demoraria para conseguir ser tão respeitado em outra empresa como sou hoje dentro

8 da empresa.

9 Eu jogaria fora todos os esforços que fiz para chegar onde cheguei dentro dessa empresa.

10 Eu teria dificuldades para ganhar um salário tão bom quanto o que tenho hoje.

Eu teria dificuldade para conseguir outro cargo que me desse o mesmo prestígio que tenho

11 com o meu cargo atual.

Eu demoraria para encontrar em outra empresa pessoas tão amigas quanto as que tenho

12 hoje entre meus colegas de trabalho.

13 Eu deixaria de receber vários benefícios que essa empresa oferece a seus funcionários.

14 Eu perderia a liberdade que tenho de realizar meu trabalho dentro dessa empresa.

15 Eu levaria muito tempo para me acostumar com um novo trabalho.

A empresa onde eu trabalho me faz sentir...

16 Animado com ela.

17 Contente com ela.

18 Entusiasmado com ela.

19 Interessado por ela.

20 Orgulhoso dela.

Sobre a empresa que eu trabalho, posso perceber...

\begin{tabular}{|c|c|c|c|c|c|c|}
\hline 21 & $\begin{array}{l}\text { Eu seria injusto com essa empresa se pedisse demissão agora e fosse trabalhar em outra } \\
\text { empresa. }\end{array}$ & 1 & 2 & & & 5 \\
\hline 22 & Seria desonesto de minha parte ir trabalhar para outra empresa agora. & 1 & 2 & & & 5 \\
\hline 23 & É minha obrigação continuar trabalhando para essa empresa. & 1 & 2 & & & 5 \\
\hline 24 & Nesse momento, essa empresa precisa de meus serviços. & 1 & 2 & & & 5 \\
\hline 25 & É a gratidão por essa empresa que me mantém ligado a ela. & 1 & 2 & & & 5 \\
\hline 26 & Essa empresa já fez muito por mim no passado. & & 2 & & & 5 \\
\hline 27 & Continuar trabalhando nessa empresa é uma forma de retribuir o que ela já fez por mim. & & & & & 5 \\
\hline
\end{tabular}

\section{PARTE II - DADOS DEMOGRÁFICOS}

\author{
Sexo: ( ) Feminino ( ) Masculino
}

Idade: anos

Tempo de Serviço: anos 
Estado Civil: ( ) Solteiro/vive só ( ) Casado/vive com alguém

$\begin{array}{clll}\text { Escolaridade: ( ) Fundamental completo } & \text { ( ) Ensino médio completo } & \text { ( ) Superior completo } \\ \text { ( ) Especialização completa } & \text { ( ) Mestrado completo } & \text { ( ) Doutorado completo } \\ \text { Função Ocupada: ( ) Não possuo função } & \text { ( ) Entre Analista I e VI } & \text { ( ) Entre Analista VII e XII } \\ & \text { ( ) Gerente Corporativo } & \text { ( ) Chefe de Departamento } & \end{array}$

